Check for updates

Cite this: Chem. Commun., 2021, 57,13780

Received 14th September 2021,

Accepted 17th November 2021

DOI: $10.1039 / \mathrm{d} 1 \mathrm{cc} 05167 \mathrm{a}$

rsc.li/chemcomm

\section{Unprecedented superstructure in the type I family of clathrates $\dagger$}

\author{
Philip Yox, ${ }^{\text {ab }}$ Oleg I. Lebedev, ${ }^{c}$ Davide Donadio (D) ${ }^{d}$ and Kirill Kovnir (D) *ab
}

\begin{abstract}
The first arsenic-based clathrate exhibiting superstructural ordering due to optimization of $\mathrm{Au}-\mathrm{As}, \mathrm{As}-\mathrm{As}$, and $\mathrm{Ba}-\mathrm{Au}$ bonding is reported. $\mathrm{Ba}_{8} \mathrm{Au}_{16} \mathrm{As}_{30}$ crystallizes in a unique $P 2_{1} / c$ monoclinic clathrate structure. The synthesis, crystal and electronic structure, and transport properties are discussed.
\end{abstract}

Clathrates have "guest atoms" that reside in cages and "framework" atoms that compose the cages. Type I clathrates are an expansive group of compounds typically crystallizing in the $P m \overline{3} n$ space group with a framework composed of tetrel elements, $\mathrm{Si}, \mathrm{Ge}$, or $\mathrm{Sn}^{1,2}$ As the type I clathrate has expanded into the regime of late transition metals and pnictogens forming the framework, there has been evidence of different superstructural orderings in selected compounds. ${ }^{3}$ Most notably, $\mathrm{Ba}_{8} \mathrm{Cu}_{16} \mathrm{P}_{30}$ crystallizes in $\mathrm{Pbcn}$ with a primitive cell containing 4 formula units. ${ }^{4,5} \mathrm{Ba}_{8} \mathrm{Au}_{16} \mathrm{P}_{30}$ was shown to be twinned down to the nano domain using transmission electron microscopy and was determined to crystallize with the same superstructure as the $\mathrm{Cu}$ analogue. ${ }^{6}$ Several ternary clathrates with late transition metals and arsenic are reported: $\mathrm{Ba}_{8} \mathrm{Cu}_{16} \mathrm{As}_{30}, \mathrm{Cs}_{8} \mathrm{Zn}_{18} \mathrm{As}_{28}$, $\mathrm{Rb}_{8} \mathrm{Zn}_{18} \mathrm{As}_{28}$, and $\mathrm{Cs}_{8} \mathrm{Cd}_{18} \mathrm{As}_{28}{ }^{7,8}$ All the arsenide-based clathrates have been reported to crystallize in the archetype clathrate I structure (cubic $P m \overline{3} n$ space group) with mixed M/As sites in the framework. Moving down the pnictogen group, a new story has emerged for antimony-based clathrates. Originally investigated in 2009, single crystal X-ray diffraction (SXRD) suggested that $\mathrm{Cs}_{8} \mathrm{Zn}_{18} \mathrm{Sb}_{28}$ and $\mathrm{Cs}_{8} \mathrm{Cd}_{18} \mathrm{Sb}_{28}$ crystallize in $P m \overline{3} n .{ }^{9}$ Recent reinvestigation has shown that the antimony-based clathrates $\mathrm{Cs}_{8} \mathrm{Zn}_{18} \mathrm{Sb}_{28}$ and $\mathrm{Cs}_{8} \mathrm{Cd}_{18} \mathrm{Sb}_{28}$ exhibit ordered superstructures with segregation of $\mathrm{M}$ and $\mathrm{Sb}$ over different framework sites as

\footnotetext{
${ }^{a}$ Department of Chemistry, Iowa State University, Ames, IA 50011, USA.

E-mail: kovnir@iastate.edu

${ }^{b}$ Ames Laboratory, U.S. Department of Energy, Ames, IA 50011, USA

${ }^{c}$ Laboratoire Crismat, Ensicaen, CNRS UMT 6508, 6 Boulevard du Marechal Juin, F-14050 Caen, France

${ }^{d}$ University of California, Davis, Davis, CA 95616, USA

† Electronic supplementary information (ESI) available. CCDC 2109533. For ESI and crystallographic data in CIF or other electronic format see DOI: 10.1039/d1cc05167a
}

evidenced using transmission electron microscopy and highresolution synchrotron X-ray powder diffraction (HR-PXRD). ${ }^{10}$ A similar ordering was found for In-Sb and Ga-Sb clathrates. ${ }^{11}$

Contrary to the observation of superstructural ordering among the phosphorous- and antimony-based clathrates, no superstructural ordering has been reported for arsenide clathrates. The superstructural ordering can be due to the energy gain attained by avoiding metal-metal bonds. In $P m \overline{3} n$, the framework filling of the $6 c, 16 i$, and $24 k$ sites cannot simultaneously fulfill the stoichiometry while avoiding metal-metal bonds and the structure is forced to reduce the overall symmetry and enlarge the unit cell volume. For phosphides, the known type I clathrates have crystallized in either $\mathrm{Pbcn}$ or $\mathrm{P4}_{2} / \mathrm{ncm}$, while the antimonides exhibited complex ordering in the $I a \overline{3}, I a \overline{3} d$, and $P 2$ space groups (the latter was proposed using microscopy studies). Herein, we report the first arsenide clathrate $\mathrm{Ba}_{8} \mathrm{Au}_{16} \mathrm{As}_{30}$ with unique superstructural ordering in the monoclinic space group $P 2_{1} / c$.

The direct synthesis from elements at $600{ }^{\circ} \mathrm{C}$ resulted in a polycrystalline sample of $\mathrm{Ba}_{8} \mathrm{Au}_{16} \mathrm{As}_{30}$. Elemental energy dispersive analysis confirms presence of only $\mathrm{Ba}, \mathrm{Au}$, and $\mathrm{As}$ in the sample. A separate reaction utilizing a CsBr/CsI flux and an excess of As resulted in crystals suitable for single crystal X-ray diffraction (SCXRD). $\mathrm{Ba}_{8} \mathrm{Au}_{16} \mathrm{As}_{30}$ crystallizes in the $P 2_{1} / c$ space group as determined using SCXRD with $a=15.147(1) \AA$, $b=15.218(1) \AA, c=10.954(1) \AA$, and $\beta=90.502(2)^{\circ}$ (Table S1, ESI $\dagger$ ). Refinement of the crystal structure shows that all atomic sites are fully occupied (Fig. 1A). Like many other pnictide clathrates with superstructures, no metal-metal $(\mathrm{Au}-\mathrm{Au})$ bonds are formed in this framework. There are five Ba positions inside the Au-As cages: Ba1@ $A_{6} \mathrm{As}_{14}, \mathrm{Ba} @ \mathrm{Au}_{8} \mathrm{As}_{12}$, Ba3@ $\mathrm{Au}_{9} \mathrm{As}_{15}$, $\mathrm{Ba} 4 @ \mathrm{Au}_{8} \mathrm{As}_{16}$, and $\mathrm{Ba} 5 @ \mathrm{Au}_{8} \mathrm{As}_{16}$. Ba1 and Ba2 occupy the $5^{12}$ pentagonal dodecahedra (Fig. 1A, red cage), while Ba3, Ba4, and Ba5 occupy the $5^{12} 6^{2}$ tetrakaidecahedra (Fig. 1A, blue cage). Although the data suggested a monoclinic space group, the lattice parameters and beta angle were suspiciously close to tetragonal symmetry. The supergroups $P m \overline{3} n, P 4_{2} / m m c$, and $P 4_{2} / n c m$ were considered as possible solutions but failed to give a good refinement. To confirm the small but robust beta angle deviation from $90^{\circ}$ and the correct 

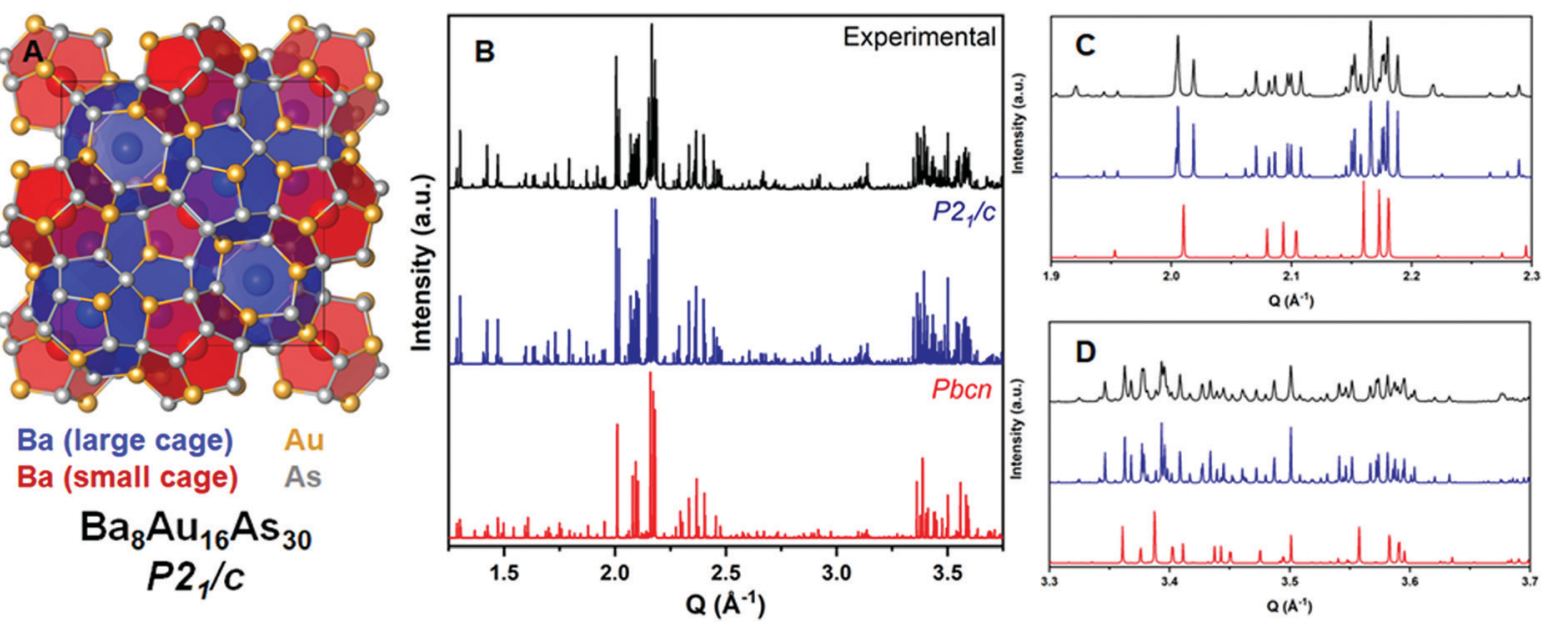

Fig. 1 (A) Crystal structure of $\mathrm{Ba}_{8} \mathrm{Au}_{16} \mathrm{As}_{30}$, Ba: blue/red; Au: gold; As: grey. (B) Experimental (black) HR-PXRD pattern and theoretical patterns for $P 2_{1} / \mathrm{C}$ (blue) and hypothetical $P b c n$ derived from $\mathrm{Ba}_{8} \mathrm{Au}_{16} \mathrm{P}_{30}$ (red); ( $C$ and $\left.\mathrm{D}\right)$ zoomed-in regions of $(\mathrm{B})$.

symmetry, a sample synthesized from elements was prepared and studied with HR-PRXD.

Aside from a few minor peaks attributed to admixtures, the calculated diffraction pattern from the single crystal model fit extremely well once the room temperature unit cell parameters $\left(a=15.197 \AA, b=15.261 \AA, c=10.979 \AA\right.$, and $\left.\beta=90.444^{\circ}\right)$ were refined (Fig. 1). HR-PXRD ruled out the aristotype cubic and orthorhombic $(\mathrm{PbCn})$ structural models. In Fig. 1C a zoomed-in region from 1.9 to $2.3 Q$ explicitly demonstrates that the $P b c n$ model fails to generate enough peaks to even begin fitting the experimental diffraction pattern. In Fig. 1D a similar conclusion can be made while noticing an agreeable peak splitting from the $P 2_{1} / c$ model and the experimentally collected data. The formation energy and stability of $\mathrm{Ba}_{8} \mathrm{Au}_{16} \mathrm{AS}_{30}$ was calculated and compared with other ternary BaAu-As phases using density functional theory (Fig. S1, ESI $\dagger$ ). The atomization energy is negative $(-0.429 \mathrm{eV}$ per atom) and $\mathrm{Ba}_{8} \mathrm{Au}_{16} \mathrm{As}_{30}$ is a thermodynamically stable phase when considering all experimentally reported binary and ternary compounds in the $\mathrm{Ba}-\mathrm{Au}-\mathrm{As}$ system. However, inclusion of the hypothetical $\mathrm{BaAu}_{2} \mathrm{As}_{4}$ (isostructural to $\left.\mathrm{BaAu}_{2} \mathrm{P}_{4}\right)^{12,13}$ shows that $\mathrm{Ba}_{8} \mathrm{Au}_{16} \mathrm{As}_{30}$ could decompose to $\mathrm{BaAu}_{2} \mathrm{As}_{4}$, BaAuAs, and Au (Fig. S1, ESI†). Our experimental efforts to synthesize $\mathrm{BaAu}_{2} \mathrm{As}_{4}$ have instead resulted in the formation of $\mathrm{Ba}_{8} \mathrm{Au}_{16} \mathrm{As}_{30}$.

The reduction of symmetry from $P m \overline{3} n$ to $P 2_{1} / c$ stems from the ordering of the framework elements (Au and As). The Bärnighausen tree (Fig. S2, ESI $\dagger$ ) shows the relationship between the two space groups as well as the Wyckoff site splitting. In the first reduction of symmetry to the space group $P 4_{2} / \mathrm{mmc}$ almost all the framework sites remain mixed occupied except for the $2 e$ site. The second transformation to $P 4_{2} / \mathrm{ncm}$ is accompanied by a doubling of the unit cell volume $(\sqrt{2} \times \sqrt{2} \times 1)$. In this space group a hypothetical distribution of Au and As among the Wyckoff sites could result in a completely ordered structure that fulfills the stoichiometry of the framework (16Au:30As) in analogy with the reported ordered structure for $\mathrm{La}_{1.6} \mathrm{Ba}_{6.4} \mathrm{Cu}_{16} \mathrm{P}_{30}{ }^{14}$ Further reduction of symmetry may be caused by optimization of the As-As and $\mathrm{Ba}-\mathrm{Au}$ interactions (Table S2, ESI $\dagger$ ). The next transformation lowers the symmetry to the orthorhombic space group Pccn. In the final transformation to $P 2_{1} / c$ all the framework sites are identified as general position $4 e$ sites and are fully occupied by either Au or As. All the Au atoms are surrounded by four As atoms and no $\mathrm{Au}-\mathrm{Au}$ distance shorter than $3.91 \AA$ is present.

The Bärnighausen tree demonstrates that single atom type site occupation is possible in $P 2_{1} / c$ but the same ordering can be accomplished in $P b c n$, as was found for $\mathrm{Ba}_{8} \mathrm{Au}_{16} \mathrm{P}_{30}$ and $\mathrm{Ba}_{8} \mathrm{Cu}_{16} \mathrm{P}_{30}$. What is the driving force for this reduction of symmetry as opposed to $P b c n$ found in $\mathrm{Ba}_{8} \mathrm{Au}_{16} \mathrm{P}_{30}$ ? In the structure of $\mathrm{Ba}_{8} \mathrm{Au}_{16} P n_{30}$ $(P n=\mathrm{P}, \mathrm{As})$ pnictogen atoms account for almost $2 / 3$ of the framework atoms. The replacement of all smaller $P$ atoms with As leads to an overall $13.7 \%$ increase of the unit cell volume per formula unit. Assuming an isotropic structure expansion in the Pbcn space group, this would lead to the increase of the Ba-framework distances and the volume of the polyhedral cages, which may become oversized for the Ba guest cations. Reducing the crystal symmetry of $\mathrm{Ba}_{8} \mathrm{Au}_{16} \mathrm{As}_{30}$ down to $P 2_{1} / c$ allows optimization of the Baframework interactions. The volumes of the Ba polyhedra in $\mathrm{Ba}_{8} \mathrm{Au}_{16} \mathrm{As}_{30}$ are $14 \%$ larger than those of the respective polyhedra in $\mathrm{Ba}_{8} \mathrm{Au}_{16} \mathrm{P}_{30}$ (Table S2, ESI $\dagger$ ). However, the average and shortest Ba-framework distances in both polyhedra increase only by $4 \%$ as compared to the distances in the phosphide analogue. The simplest model of $P b c n \mathrm{Ba}_{8} \mathrm{Au}_{16} \mathrm{As}_{30}$ was produced using the atomic coordinates of $\mathrm{Ba}_{8} \mathrm{Au}_{16} \mathrm{P}_{30}$ and isotropically expanding the volume per formula unit to match that of $\mathrm{Ba}_{8} \mathrm{Au}_{16} \mathrm{As}_{30}$. The analysis of the consequent atomic distances shows that for cages of the same volume, $P 2_{1} / c$ allows for optimized Ba-Au distances (Table S2.2, ESI $\dagger$ ). Relaxing of the produced hypothetical $P b c n \mathrm{Ba}_{8} \mathrm{Au}_{16} \mathrm{As}_{30}$ using DFT still results in the structure with $\sim 0.1 \AA$ longer $\mathrm{Ba}-\mathrm{Au}$ distances, e.g. the shortest $\mathrm{Ba}-\mathrm{Au}$ distance in relaxed $\mathrm{Pbcn}$ is $3.49 \AA$ while in $P 2_{1} / c$ the shortest Ba-Au distance is $3.39 \AA$. Another important difference between $\mathrm{Ba}_{8} \mathrm{Au}_{16} \mathrm{As}_{30}$ and $\mathrm{Ba}_{8} \mathrm{Au}_{16} \mathrm{P}_{30}$ is the pnictogen-pnictogen bonding. While there are no $\mathrm{Au}-\mathrm{Au}$ bonds in either structure, there are homoatomic pnictogen-pnictogen bonds. The sum of covalent radii for $\mathrm{P}$ is $2.20 \AA$ while the sum of covalent radii for $\mathrm{As}$ is $2.40 \AA$. In the case of $\mathrm{Ba}_{8} \mathrm{Au}_{16} \mathrm{P}_{30}$, very long P-P bonds 
are observed with distances up to $2.72 \AA^{6}{ }^{6}$ This is not the case for $\mathrm{Ba}_{8} \mathrm{Au}_{16} \mathrm{As}_{30}$ where the longest As-As distance is $2.53 \AA$. The Zintl phases $\mathrm{Ba}_{3} \mathrm{As}_{14}{ }^{15}$ and $\mathrm{Ba}_{2} \mathrm{As}_{7} \mathrm{I}^{16}$ feature $\mathrm{As}_{7}$ clusters where the longest As-As bond is 2.52-2.53 $\mathrm{A}$, while $\mathrm{BaAs}_{2}{ }^{17}$ features one-dimensional As chains with a longest distance of $2.50 \AA$, which suggests that the AsAs distances in $\mathrm{Ba}_{8} \mathrm{Au}_{16} \mathrm{As}_{30}$ are not unusual. The substantial differences between $\mathrm{Ba}_{8} \mathrm{Au}_{16} \mathrm{As}_{30}$ and $\mathrm{Ba}_{8} \mathrm{Au}_{16} \mathrm{P}_{30}$ are in the polypnictide anions. While there are two fragments in $\mathrm{Ba}_{8} \mathrm{Au}_{16} \mathrm{P}_{30}, \mathrm{P}_{12}$ and $\mathrm{P}_{18}$, only one type of As fragment, $\mathrm{As}_{15}$, exists in $\mathrm{Ba}_{8} \mathrm{Au}_{16} \mathrm{As}_{30}$ (Fig. S3, ESI $\dagger$ ). We hypothesize that the differences in the superstructural ordering for $\mathrm{Ba}_{8} \mathrm{Au}_{16} \mathrm{As}_{30}$ and $\mathrm{Ba}_{8} \mathrm{Au}_{16} \mathrm{P}_{30}$ are due to optimization of pnictogen-pnictogen bonding and $\mathrm{Ba}-\mathrm{Au}$ interactions.

To confirm the superstructural ordering determined using HR-PXRD and SCXRD, transmission electron microscopy was employed. The selected area electron diffraction (ED) patterns collected from the main crystallographic zone axes show agreement with the $P 2_{1} / c$ space group determined using the other methods (Fig. 2). In the [001] zone axis, the absence of 4-fold symmetry excludes tetragonal or cubic symmetry and the absence of the (010) diffraction peak is in line with the systematic absence condition for $0 k 0, k=2 n$, which is a general condition for $P 2_{1} / c$ as well as $P c c n$. The presence of the (100) reflection shows that Pccn cannot be used to index the ED patterns, because of the violation of the $h 00, h=2 n$ condition. The [011] zone axis, which corresponds to [111] in the cubic aristotype structure, confirms an absence of the 3 -fold rotation axis and shows only the presence of two-fold symmetry. This zone confirms the presence of the (100) reflection seen in the [001].
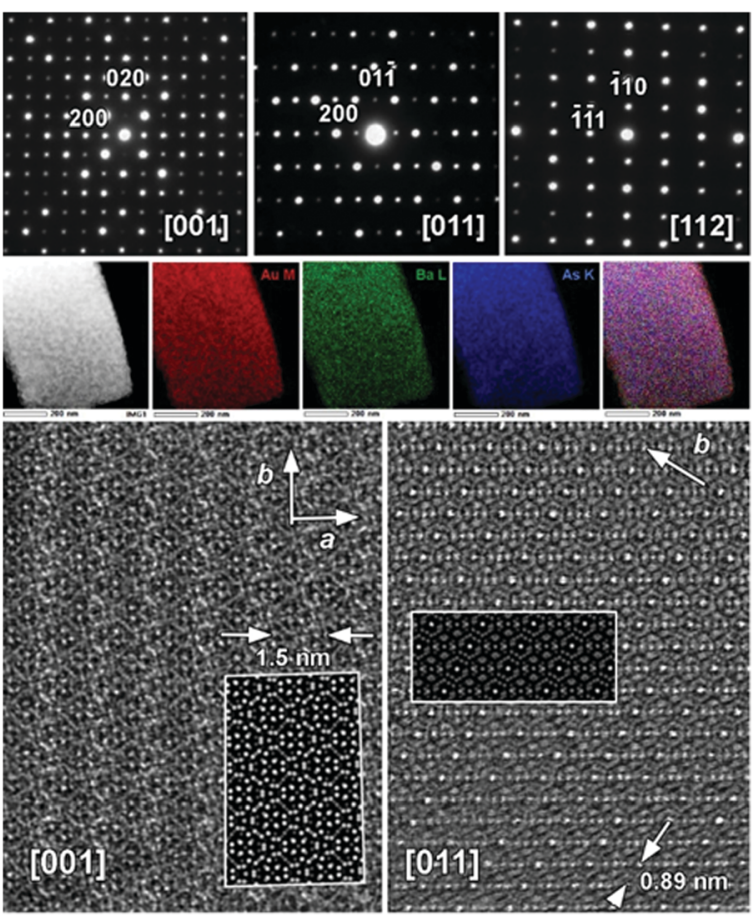

Fig. 2 Top: ED of the [001], [011], and [112] zones of $\mathrm{Ba}_{8} \mathrm{Au}_{16} \mathrm{As}_{30}$ indexed in the $P 2_{1} / C$ model; middle: low magnification HAADF-STEM image of the single crystallite and the corresponding EDX elemental mapping of Au M (red), Ba L (green), As K (blue), and the overplayed image; bottom: high resolution [011] and [112] HAADF-STEM images. The simulated images are given as insets.
Elemental mapping and high resolution HAADF-STEM imaging show the homogeneous distribution of all chemical elements within a composition close to nominal (As - 54.6 at\%, $\mathrm{Ba}-15.0$ at $\%$, and $\mathrm{Au}-31.8$ at $\%$ ) and good crystallinity (free of twinning and defects). The simulated high resolution [001] and [011] HAADF-STEM images are in agreement with the experimental ones (inset in Fig. 2, bottom panel).

Low thermal conductivity is ubiquitous among clathrates. ${ }^{2}$ The large number of atoms in the unit cell and the rattling guest atoms give rise to localized modes, which reduces the lattice contribution to thermal conductivity ( $\left.\kappa_{\text {lattice }}\right)$. Additionally, the presence of heavy atoms in the framework reduces $\kappa_{\text {lattice }}$ by lowering the optical phonon frequency range. Au is the third heaviest atom that has been incorporated into the framework of any clathrate, behind $\mathrm{Bi}$ and $\mathrm{Hg}^{2,18-20}$ The incorporation of $\mathrm{Au}$ and other heavy framework atoms has been shown to lower the thermal conductivity significantly. For the $\mathrm{Ba}_{8} \mathrm{Ga}_{16-3 x} \mathrm{Au}_{x} \mathrm{Ge}_{30+2 x}$ system, substitution of $\mathrm{Au}(x=4)$ lowered the lattice thermal conductivity from $1.6 \mathrm{~W} \mathrm{~K}^{-1} \mathrm{~m}^{-1}$ in $\mathrm{Ba}_{8} \mathrm{Ga}_{16} \mathrm{Ge}_{30}$ to $1.0 \mathrm{~W} \mathrm{~K}{ }^{-1} \mathrm{~m}^{-1} \cdot{ }^{21} \mathrm{Ba}_{8} \mathrm{Au}_{16} \mathrm{P}_{30}$ has an exceptionally low lattice thermal conductivity even for clathrates. ${ }^{6}$ Considering the substitution of As for $\mathrm{P}$ it is reasonable to expect an even further reduction of the $\kappa_{\text {lattice }}$ for $\mathrm{Ba}_{8} \mathrm{Au}_{16} \mathrm{As}_{30}$. However, that is not the case. As seen in Fig. 3, the lattice thermal conductivity for $\mathrm{Ba}_{8} \mathrm{Au}_{16} \mathrm{As}_{30}$ is $\sim 0.85 \mathrm{~W} \mathrm{~K} \mathrm{~K}^{-1} \mathrm{~m}^{-1}$ at room temperature. The thermal conductivity is comparable to that for $\mathrm{Ba}_{8} \mathrm{Au}_{6} \mathrm{Ge}_{40}$ considering that $\mathrm{Ge}$ and As are comparable in atomic mass and $\mathrm{Ba}_{8} \mathrm{Au}_{16} \mathrm{As}_{30}$ has substantially more $\mathrm{Au}$ allowing the lattice thermal conductivity to be lowered from $\sim 1.0 \mathrm{~W} \mathrm{~K}^{-1} \mathrm{~m}^{-1}$ for $\mathrm{Ba}_{8} \mathrm{Au}_{6} \mathrm{Ge}_{40}{ }^{21}$ to $\sim 0.85 \mathrm{~W} \mathrm{~K}^{-1} \mathrm{~m}^{-1}$ for $\mathrm{Ba}_{8} \mathrm{Au}_{16} \mathrm{As}_{30}$. The thermal conductivity of $\mathrm{Ba}_{8} \mathrm{Au}_{16} \mathrm{As}_{30}$ is lower than most type I clathrates including $\mathrm{Ba}_{8} \mathrm{Cu}_{16} \mathrm{P}_{30}$ however it is still $\sim 50 \%$ higher than $\mathrm{Ba}_{8} \mathrm{Au}_{16} \mathrm{P}_{30}$. It may be that $\mathrm{Ba}_{8} \mathrm{Au}_{16} \mathrm{P}_{30}$ is an outlier due to an extrinsic lowering of the thermal conductivity caused by the grain boundaries and nanoscale twinning detected using HAADF-STEM. ${ }^{6}$ The extent of the twinning in $\mathrm{Ba}_{8} \mathrm{Au}_{16} \mathrm{As}_{30}$ is currently unknown but the presence of twinning to nano-domains seems unlikely as a structural solution from a single crystal was easily obtained and no twinning was detected during HAADF-STEM studies.

$\mathrm{Ba}_{8} \mathrm{Au}_{16} \mathrm{As}_{30}$ exhibits a metal-like temperature behavior of electrical resistivity with values similar to that for $\mathrm{Ba}_{8} \mathrm{Au}_{16} \mathrm{P}_{30}$. This is expected for compositions that are not electron balanced. $\mathrm{Ba}_{8} \mathrm{Au}_{16} \mathrm{As}_{30}$ has 182 electrons per 46 framework atoms, $8 \times 2(\mathrm{Ba})+16 \times 1(\mathrm{Au})+30 \times 5(\mathrm{As})=182$, while an electron balanced composition requires $46 \times 4=184$ electrons. Electronic structure calculations confirm the expected metallic nature of $\mathrm{Ba}_{8} \mathrm{Au}_{16} \mathrm{As}_{30}$. The Fermi level is about $0.25 \mathrm{eV}$ below the maximum of the valence band, which makes this material p-type. The Seebeck coefficient of $\mathrm{Ba}_{8} \mathrm{Au}_{16} \mathrm{As}_{30}$ is positive and increases with temperature. The room temperature absolute value $\left(13 \mu \mathrm{V} \mathrm{K}^{-1}\right)$ is close to those for other metallic pnictide clathrates, such as $\mathrm{Ba}_{8} \mathrm{Au}_{16} \mathrm{P}_{30}\left(15 \mu \mathrm{V} \mathrm{K}^{-1}\right)^{6}$ and $\mathrm{Cs}_{8} \mathrm{Cd}_{18} \mathrm{As}_{28}$ $\left(11 \mu \mathrm{V} \mathrm{K}^{-1}\right) .{ }^{8}$ The major charge carriers are holes, which is expected for an electron deficient clathrate. The absolute values for the Seebeck coefficient below $75 \mathrm{~K}$ were lower than $1 \mu \mathrm{V} \mathrm{K}{ }^{-1}$ and were 

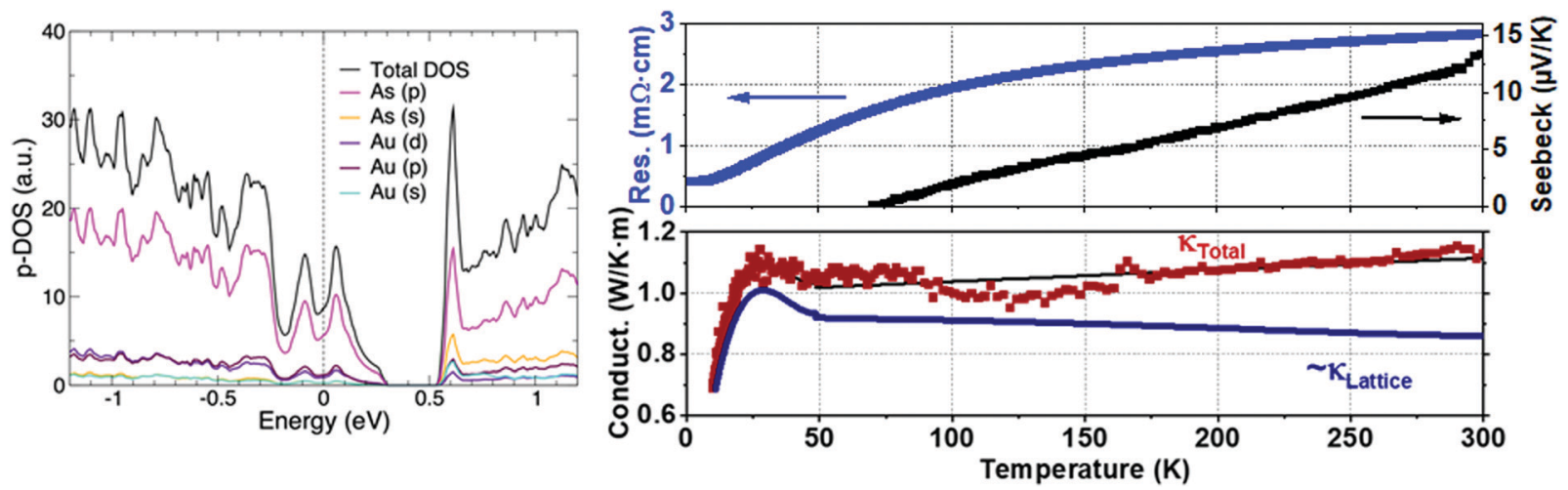

Fig. 3 Left: projected density of states in the GGA+U approximation. Right: temperature dependence of resistivity (blue), Seebeck coefficient (black), and thermal conductivity (red). The total thermal conductivity trend is shown with a black line to guide the eye.

omitted due to a high level of noise. While the Seebeck coefficient is low; $z T \sim 2.2 \times 10^{-3}$, the low thermal conductivity and electron deficiency means that $\mathrm{Ba}_{8} \mathrm{Au}_{16} \mathrm{As}_{30}$ is well positioned for substitution and alloying to optimize the electronic transport properties, as was shown for clathrates developed from $\mathrm{Ba}_{8} \mathrm{Cu}_{16} \mathrm{P}_{30} \cdot{ }^{14,22-24}$ To probe potential of $\mathrm{Ba}_{8} \mathrm{Au}_{16} \mathrm{As}_{30}$ for thermoelectric applications, the transport properties were calculated as a function of the energy of the Fermi level (Fig. S4, ESI $\dagger$ ). Shifting the Fermi level via substitutional doping to the top of the valence band increases the Seebeck coefficient by an order of magnitude. However, the resistivity also increased by a similar amount. Due to the counteracting effects of resistivity and Seebeck coefficient, the overall $z T$ of the material did not surpass 0.07 . Even if the material was doped to n-type, $z T$ will not exceed 0.1 (Fig. S4, ESI $\dagger$ ). These results indicate that only modifying the carrier concentration will not provide a feasible route to a "state-of-the-art" thermoelectric material. Adjusting the holemobility may be an alternative route to further increase the thermoelectric performance of $\mathrm{Ba}_{8} \mathrm{Au}_{16} \mathrm{As}_{30}$, as was demonstrated for $\mathrm{La}_{x} \mathrm{Ba}_{8-x} \mathrm{Cu}_{16} \mathrm{P}_{30}{ }^{14}$

In conclusion, $\mathrm{Ba}_{8} \mathrm{Au}_{16} \mathrm{As}_{30}$ is a new type I clathrate crystallizing in the unprecedented superstructural space group $P 2_{1} / c$ that features a singular repeating As fragment and the absence of $\mathrm{Au}-\mathrm{Au}$ bonds. We hypothesize that factors such as cage volume, and optimization of the $\mathrm{Au}-\mathrm{As}$, As-As, and Ba-framework interactions are the reasons for $\mathrm{Ba}_{8} \mathrm{Au}_{16} \mathrm{AS}_{30}$ crystallizing in a different superstructure compared to $\mathrm{Ba}_{8} \mathrm{Au}_{16} \mathrm{P}_{30}$. The transport properties of $\mathrm{Ba}_{8} \mathrm{Au}_{16} \mathrm{As}_{30}$ are expected for a metallic clathrate but point to $\mathrm{Ba}_{8} \mathrm{Au}_{16} \mathrm{P}_{30}$ as an outlier in terms of its thermal conductivity. The theoretical transport properties indicate that modification of carrier mobility is required to substantially increase the $z T$ of $\mathrm{Ba}_{8} \mathrm{Au}_{16} \mathrm{AS}_{30^{-}}$ based thermoelectric materials.

The authors would like to thank Dr Saul Lapidus (APS) for help collecting synchrotron the HR-PXRD data and Prof. J. Zaikina (ISU) for access to the SPS. This research was supported by the U.S. Department of Energy, Office of Basic Energy Sciences, Division of Materials Science and Engineering, grant DE-SC0022288. This research used resources of the Advanced Photon Source, a U.S. Department of Energy (DOE) Office of Science User Facility, operated for the DOE Office of Science by Argonne National Laboratory under Contract No. DE-AC02-06CH11357.

\section{Conflicts of interest}

There are no conflicts to declare.

\section{References}

1 G. Nolas, The Physics and Chemistry of Inorganic Clathrates, Springer, Netherlands, 1 edn, 2014.

2 J.-A. Dolyniuk, B. Owens-Baird, J. Wang, J. V. Zaikina and K. Kovnir, Mater. Sci. Eng., 2016, 108, 1-46.

3 J. Wang, J.-A. Dolyniuk and K. Kovnir, Acc. Chem. Res., 2018, 51, 31-39.

4 J. Dünner and A. Mewis, Z. Anorg. Allg. Chem., 1995, 621, 191-196.

5 D. Huo, T. Sasakawa, Y. Muro and T. Takabatake, Appl. Phys. Lett., 2003, 82, 2640-2642.

6 J. Fulmer, O. I. Lebedev, V. V. Roddatis, D. C. Kaseman, S. Sen, J.-A. Dolyniuk, K. Lee, A. V. Olenev and K. Kovnir, J. Am. Chem. Soc., 2013, 135, 12313-12323.

7 K. Wei, A. R. Khabibullin, D. Hobbis, W. Wong-Ng, T. Chang, S. G. Wang, I. Levin, Y.-S. Chen, L. M. Woods and G. S. Nolas, Inorg. Chem., 2018, 57, 9327-9334.

8 H. He, A. Zevalkink, Z. M. Gibbs, G. J. Snyder and S. Bobev, Chem. Mater., 2012, 24, 3596-3603.

9 Y. Liu, L.-M. Wu, L.-H. Li, S.-W. Du, J. D. Corbett and L. Chen, Angew. Chem., 2009, 121, 5409-5412.

10 B. Owens-Baird, P. Yox, S. Lee, X. B. Carroll, S. Grass Wang, Y.-S. Chen, O. I. Lebedev and K. Kovnir, Chem. Sci., 2020, 11, 10255-10264.

11 B. Owens-Baird, J. Wang, S. G. Wang, Y.-S. Chen, S. Lee, D. Donadio and K. Kovnir, J. Am. Chem. Soc., 2020, 142, 2031-2041.

12 J. E. Saal, S. Kirklin, M. Aykol, B. Meredig and C. Wolverton, JOM, 2013, 65, 1501-1509.

13 J. Fulmer, D. Kaseman, J. Dolyniuk, K. Lee, K. S. Sen and K. Kovnir, Inorg. Chem., 2013, 52, 7061-7067.

14 J. Wang, Y. He, N. E. Mordvinova, O. I. Lebedev and K. Kovnir, Chem, 2018, 4, 1465-1475.

15 W. Schmettow and H. G. Von Schnering, Angew. Chem., Int. Ed. Engl., 1977, 16, 857.

16 J.-A. Dolyniuk, S. Lee, N. Tran, J. Wang, L.-L. Wang and K. Kovnir, J. Solid State Chem., 2018, 263, 195-202.

17 F. Emmerling, D. Petri and C. Röhr, Z. Anorg. Allg. Chem., 2004, 630, 2490-2501.

18 T. F. Fassler and C. Kronseder, Z. Anorg. Allg. Chem., 1998, 624, 561-568. 19 A. Kaltzoglou, S. Ponou and T. F. Fässler, Eur. J. Inorg. Chem., 2008, 4507-4510. 20 A. Kaltzoglou, S. Ponou and T. F. Fässler, Z. Anorg. Allg. Chem., 2008, 538-542. 21 Z. Ye, J. Y. Cho, M. M. Tessema, J. R. Salvador, R. A. Waldo, J. Yang, H. Wang, W. Cai, M. J. Kirkham, J. Yang and W. Zhang, J. Alloys Compd., 2014, 587, 747-754.

22 J. Wang, O. I. Lebedev, K. Lee, J.-A. Dolyniuk, P. Klavins, S. Bux and K. Kovnir, Chem. Sci., 2017, 8, 8030-8038.

23 J. Dolyniuk, P. S. Whitfield, K. Lee, O. I. Lebedev and K. Kovnir, Chem. Sci., 2017, 8, 3650-3659.

24 J. Dolyniuk, J. Wang, M. Marple, S. Sen, Y. Cheng, A. J. RamirezCuesta and K. Kovnir, Chem. Mater., 2018, 30, 3419-3428. 